\title{
Extended-pulsed fidaxomicin versus vancomycin in patients 60 years and older with Clostridium difficile infection: cost-effectiveness analysis in Spain
}

\author{
Carlos Rubio-Terrés ${ }^{1}$. José María Aguado ${ }^{2}$ - Benito Almirante ${ }^{3}$. Javier Cobo ${ }^{4}$ - Santiago Grau ${ }^{5}$. Miguel Salavert ${ }^{6}$. \\ Elena González Antona Sánchez ${ }^{7}$. Cristina López Gutiérrez ${ }^{7}$. Darío Rubio-Rodríguez ${ }^{1}$
}

Received: 22 October 2018 / Accepted: 4 February 2019 /Published online: 13 April 2019

(C) The Author(s) 2019

\begin{abstract}
The cost of treating Clostridium difficile infection (CDI) in Spain is substantial. Findings from the randomised, controlled, open-label, phase 3b/4 EXTEND study showed that an extended-pulsed fidaxomicin (EPFX) regimen was associated with improved sustained clinical cure and reduced recurrence of CDI versus vancomycin in patients aged 60 years and older. We assessed the cost-effectiveness of EPFX versus vancomycin for the treatment of CDI in patients aged 60 years and older from the perspective of the National Health System (NHS) in Spain. We used a Markov model with six health states and 1-year time horizon. Health resources, their unit costs and utilities were based on published sources. Key efficacy data and transition probabilities were obtained from the EXTEND study and published sources. A panel of Spanish clinical experts validated all model assumptions. In the analysis, 0.638 and 0.594 quality-adjusted life years (QALYs) per patient were obtained with EPFX and vancomycin, respectively, with a gain of 0.044 QALYs with EPFX. The cost per patient treated with EPFX and vancomycin was estimated to be $€ 10,046$ and $€ 10,693$, respectively, with a saving of $€ 647$ per patient treated with EPFX. For willingness-to-pay thresholds of $€ 20,000, € 25,000$ and $€ 30,000$ per QALY gained, the probability that EPFX was the most cost-effective treatment was $99.3 \%, 99.5 \%$ and $99.9 \%$, respectively. According to our economic model and the assumptions based on the Spanish NHS, EPFX is costeffective compared with vancomycin for the first-line treatment of CDI in patients aged 60 years and older.
\end{abstract}

Keywords Clostridium difficile infection $\cdot$ Cost-effectiveness $\cdot$ Extended-pulsed fidaxomicin $\cdot$ Fidaxomicin $\cdot$ Vancomycin

Electronic supplementary material The online version of this article (https://doi.org/10.1007/s10096-019-03503-4) contains supplementary material, which is available to authorized users.

Darío Rubio-Rodríguez

drubiorodriguez@healthvalue.org

Health Value, C/ Virgen de Aránzazu, 21. $5^{\circ}$ B, 28034 Madrid, Spain

2 Department of Infectious Diseases, Hospital Universitario 12 de Octubre, Madrid, Spain

3 Department of Infectious Diseases, Hospital Universitario Vall d'Hebron, Barcelona, Spain

4 Department of Infectious Diseases, Hospital Universitario Ramón y Cajal/IRYCIS, Madrid, Spain

5 Department of Pharmacy, Hospital del Mar, Barcelona, Spain

6 Department of Infectious Diseases, Hospital Universitario La Fe, Valencia, Spain

7 Astellas Pharma S.A., Madrid, Spain

\section{Introduction}

Clostridium difficile is the most frequent bacterial cause of hospital-acquired diarrhoea [1]. The annual incidence of CDI in Spain is estimated at 17.1 cases per 10,000 hospitalised patients [2], ranging from 12.2 to 24.0 cases per 10,000 hospitalisations [3, 4]. A study from the United Kingdom found that the rate of hospital mortality is much higher for patients with hospital-acquired CDI (15.3\%) than for those without CDI (1.9\%), with infection also substantially increasing the length of stay [5].

One study estimated that 7600 episodes of CDI occurred annually in Spain, with an economic burden of $€ 32,157,093$ to the National Health System (NHS) [6]. A study from the USA determined that recurrent $\mathrm{CDI}$ was associated with significantly greater likelihood of readmission to hospital ( $85 \%$ vs $41 \%$, respectively; $p<0.001)$ and longer length of stay when 
readmitted (mean 18.6 vs 7.6 , respectively; $p<0.001$ ) than those patients without recurrent CDI [7]. A recent economic review of published studies reporting CDI-associated burden revealed that in Spain, hospitalisation costs attributable to CDI among all patients were $€ 4265$ per patient, rising to $€ 4885$ per patient among those aged $>65$ years [8]. Furthermore, there was an incremental rise in the cost of treating an initial CDI episode (€3901), first recurrence (€4875) and second recurrence (€5916), with hospitalisation accounting for $96 \%$ of costs [8].

Patients with CDI should be managed by discontinuing any antibiotic that might have affected the normal microbial ecology of the large intestine and the use of which favours the proliferation of $C$. difficile, which releases toxins that induce an inflammatory response $[1,9]$. Guideline-recommended antibiotic treatments for initial, non-severe CDI include fidaxomicin, vancomycin [10] or metronidazole [11]. However, recurrent infection is common, occurring in up to $25 \%$ of cases treated with vancomycin or metronidazole [12]. Recurrence may be due, among other reasons, to delayed recovery of the intestinal microbiota previously disrupted by CDI-directed treatment [13].

Fidaxomicin is a narrow spectrum macrocyclic antibiotic indicated for the treatment of CDI in adults at a dose of $200 \mathrm{mg}$ twice daily for 10 days $[11,14]$ and has been associated with greater preservation of the intestinal microbiota than vancomycin [15]. Fidaxomicin treatment also significantly lowers the incidence of recurrent CDI compared with vancomycin [16-18]. A validated in vitro human gut model showed that an extended-pulsed fidaxomicin (EPFX) regimen enables the persistence of fidaxomicin at concentrations inhibitory to $C$. difficile, facilitating intestinal microbiota recovery [19]. The efficacy and safety of the EPFX regimen $(200 \mathrm{mg}$ oral fidaxomicin twice daily on days $1-5$, followed by oncedaily administration on alternate days on days 7-25), which uses the same number of tablets as the standard fidaxomicin regimen, were compared with standard vancomycin (125 mg orally, four times daily on days 1-10) in the EXTEND randomised, controlled trial of patients 60 years and older with CDI [20]. The primary endpoint of sustained clinical cure rate 30 days after the end of treatment (day 55 for EPFX and day 40 for vancomycin; defined as clinical response at test of cure and no recurrence of CDI) was significantly higher with EPFX (70\%) compared with vancomycin $(59 \% ; p=0.030)$. Until day 90 , the rate of sustained clinical cure was significantly higher and recurrence was significantly lower in the EPFX than the vancomycin arm $(p \leq 0.007$ and $p \leq$ 0.001 , respectively) [20]. An economic analysis of these data found that the reduced recurrence rate with EPFX made this regimen more cost-effective than vancomycin for first-line treatment of CDI in older patients from the perspective of the United Kingdom NHS [21].

The objective of the present study was to evaluate the cost-effectiveness of EPFX compared with vancomycin for the treatment of CDI in patients aged 60 years and older from the perspective of the NHS in Spain.

\section{Methods}

\section{Model design}

Evaluation of the cost-effectiveness of CDI therapy encompasses appraisal of the initial episode and subsequent treatments for CDI recurrence(s). A cohort-based Markov model $[22,23]$ consisting of six mutually exclusive health states (Fig. 1) was used, evaluating up to three treatment courses. The characteristics of this model have been described previously in an adaptation to the NHS in England [21]. Briefly, the cohort of patients with CDI moved between health states, according to transition probabilities obtained from clinical studies, in discrete periods of time called cycles (every 5 days in the model). During each cycle patients moved between the health states, generating costs and utilities, which represented quality of life on a standard scale of 0 (dead) to 1 (full health), allowing quality-adjusted life years (QALYs) to be estimated, during a time horizon of 1 year [24].

In accordance with the EXTEND study, our model assumed that patients aged 60 years and older with CDI received treatment with EPFX (200 mg oral fidaxomicin tablets twice

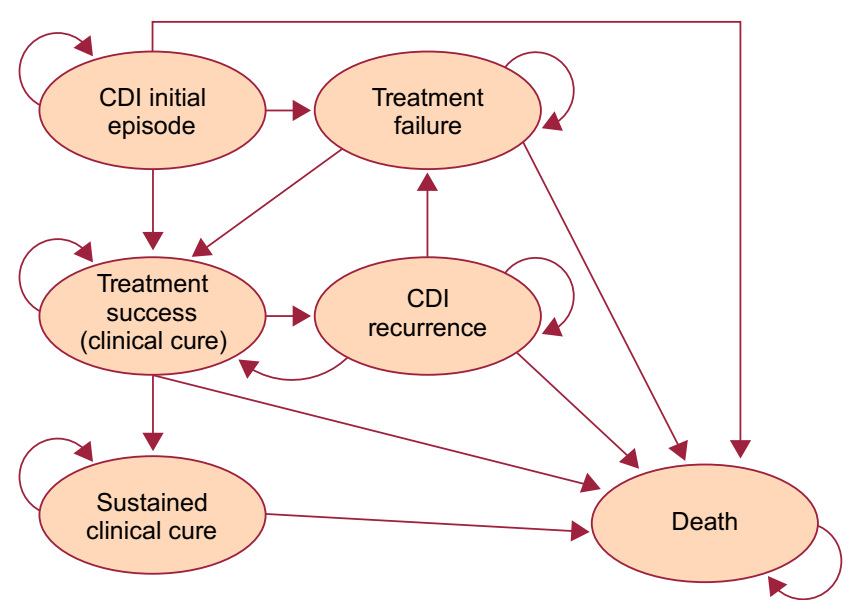

Fig. 1 Overview of clinical pathways and health states used in the Markov model. CDI, Clostridium difficile infection. Reproduced with kind permission from Watt $\mathrm{M}$, McCrea C. Cost-effectiveness of extended-pulsed fidaxomicin versus vancomycin in older patients with Clostridium difficile infection in England. Poster presented at the 27th European Congress of Clinical Microbiology and Infectious Diseases 2017, 22-25 April, Vienna, Austria 
Table 1 Treatment sequences considered in the model

First treatment

Interventional scenario

Initial CDI episode

First CDI recurrence

Second CDI recurrence

Comparator scenario

Initial CDI episode

First CDI recurrence

Second CDI recurrence
EPFX

EPFX
High-dose vancomycin
FMT
Vancomycin 10 days $^{\mathrm{d}}$
EPFX
FMT

Treatment received upon first

treatment failure
Treatment received upon second treatment failure

$C D I$ Clostridium difficile infection, EPFX extended-pulsed fidaxomicin, FDX fidaxomicin, $F M T$ faecal microbiota transplantation

a Tapered vancomycin regimen: $125 \mathrm{mg}$ four times daily oral vancomycin for 14 days, followed by $125 \mathrm{mg}$ twice-daily oral vancomycin for 7 days, followed by $125 \mathrm{mg}$ once-daily oral vancomycin for 7 days and finally, $125 \mathrm{mg}$ oral vancomycin every 3 days, giving a total of 8 weeks of treatment

${ }^{\mathrm{b}}$ FDX 10 days: standard-regimen fidaxomicin consisting of $200 \mathrm{mg}$ twice daily for 10 days

${ }^{\mathrm{c}}$ High-dose vancomycin: dose increased to $250 \mathrm{mg}$ four-times daily for 10 days in $80 \%$ of patients and up to $500 \mathrm{mg}$ four times daily in $20 \%$ of patients

${ }^{\mathrm{d}}$ Vancomycin 10 days: standard-regimen vancomycin consisting of $125 \mathrm{mg}$ four times daily for 10 days

daily on days $1-5$, followed by once-daily administration on alternate days on days $7-25)$ or vancomycin (125 mg oral capsules, four-times daily on days 1-10) [20]. In our analysis, the hypothetical patient cohort entered the model with an initial CDI episode and received first-line treatment with EPFX or vancomycin (Fig. 1). Further management assumptions are described in Online Resource 1.

Owing to the paucity of information from clinical practice in Spain regarding the choice of therapy for repeated CDI recurrences and for second- or third-line treatment of CDI, treatment choice was estimated by the panel of clinical experts (authors JMA, BA, JC, SG, MS; Table 1). In this regard, several assumptions were made in the model, which are described in Online Resource 1 [10, 23].

\section{Model inputs}

\section{Clinical}

Comparative clinical and safety data for the EPFX and vancomycin regimens in the treatment of CDI, as well as the model's main transition probabilities, including death, were obtained from the EXTEND clinical trial [20, 21] (Table 2). Detailed descriptions of other clinical inputs are in Online Resource 2. All clinical inputs were assumed to be the same for the first, second and third treatment courses [21].

\section{Costs}

Healthcare resources and the corresponding unit costs considered in the model were obtained from Spanish sources (see Online Resource 3; Table ESM 1) [6, 21, 23, 25-27]. Detailed information on cost inputs are available in Online Resource 3. The analysis was performed from the perspective of the NHS in Spain, and

Table 2 Summary of clinical inputs (cure, recurrence), adverse events and mortality included in the model

\begin{tabular}{lll}
\hline Item & EPFX & Vancomycin \\
\hline Clinical cure, \% [20] & $N=177$ & $N=179$ \\
Clinical cure 2 days after EOT & 78.0 & 82.1 \\
Risk of recurrence, \% [20] & $N=138$ & $N=147$ \\
Recurrence at day 40 & 1.4 & 19.7 \\
Recurrence at day 55 & 4.3 & 21.1 \\
Recurrence at day 90 & 7.2 & 22.4 \\
Incidence of adverse events, \% [20] & $N=181$ & $N=181$ \\
Anaemia & 2.8 & 5.5 \\
Heart failure & 2.2 & 5.5 \\
Constipation & 5.5 & 2.8 \\
Diarrhoea & 5.5 & 6.6 \\
Fever & 3.9 & 6.6 \\
CDI & 3.9 & 13.3 \\
Pneumonia & 2.8 & 5.5 \\
Sepsis & 0.6 & 5.0 \\
Urinary tract infection & 3.3 & 6.6 \\
Mortality, \% [20] & $N=183$ & $N=181$ \\
Days 0-10 & 1.4 & \\
Days 11-15 & 1.3 & \\
Days 16-25 & 1.2 & \\
Days 26-30 & 1.0 & \\
Days 31-90 & 0.9 & \\
After day 90 & 0 & \\
\hline & & \\
\hline
\end{tabular}

$E P F X$ extended-pulsed fidaxomicin, EOT end of treatment, $C D I$ Clostridium difficile infection 
only direct healthcare costs expressed in Euros $(€)$ from 2017 were considered.

\section{Utilities}

QALYs were calculated from CDI-associated utilities (the quantification of patient-perceived quality of life), obtained from previous studies by Wilcox et al. [28] and Slobogean et al. [29]. The loss of utilities related to adverse events was obtained from several published studies [30-33] (see Online Resource 3, Table ESM 1).

\section{Model outputs and sensitivity analyses}

Results are presented as an incremental cost-effectiveness ratio (ICER), i.e., the cost of gaining one QALY with EPFX compared with vancomycin. A base case (deterministic) analysis was performed, incorporating the mean values of all variables. Several sensitivity analyses were also performed: the duration of hospital stay attributable to CDI was modified, taking the 4 days estimated by Monge et al. [34] into consideration; the impact of outlying values of all the model's variables was assessed; and finally, the cost of an episode of CDI recurrence was considered to be three times greater than that of an initial episode of CDI [21]. The impact of different probabilities for utilities and costs was assessed using 1000 Monte Carlo simulations [35]. Three willingness-to-pay thresholds were considered: $€ 20,000, € 25,000$ and $€ 30,000$ per QALY achieved with EPFX compared with vancomycin [36, 37].

\section{Results}

\section{Base case}

Applying the EXTEND study outcomes of clinical response to CDI treatment and recurrence (Tables 2 and ESM 1 and Guery et al. [20]) in the model over a time horizon of 1 year, the base case (deterministic) analysis showed 0.638 and 0.594 QALYs per patient treated with EPFX and vancomycin, respectively, a gain of 0.044 QALYs with EPFX (Table 3). Over a 1-year time horizon, the associated treatment cost per patient was $€ 10,046$ with EPFX and $€ 10,693$ with vancomycin. This would result in a cost saving of $€ 647$ per patient treated with EPFX compared with vancomycin. Consequently, EPFX was the dominant treatment associated with higher QALY and lower cost compared with vancomycin (Table 3).

\section{Deterministic sensitivity analysis}

Sensitivity analyses (Online Resource 4, Table ESM 2) showed that the variables with the greatest influence on outcome were the relative probability of clinical cure with first-line treatment EPFX compared with vancomycin, hospitalisation costs associated with EPFX treatment (days 5-10), the relative risk of recurrence with EPFX compared with vancomycin after 90 days and the utility associated with sustained clinical cure after first recurrence. In all scenarios, EPFX was the dominant treatment versus vancomycin (Online Resource 4, Table ESM 2). Taking into consideration the CDI-attributable hospital stay of 4 days, the sensitivity analysis showed that EPFX was dominant over vancomycin. Given that the cost of a recurrent CDI episode is three times higher than that of an initial episode, the cost per QALY gained with EPFX was $€ 2747$ versus vancomycin; therefore, EPFX would be cost effective.

\section{Probabilistic sensitivity analysis}

In the probabilistic analysis, EPFX and vancomycin were associated with costs of $€ 10,051$ and $€ 10,697$, respectively, with a cost saving of $€ 646$ per patient treated with EPFX. EPFX was therefore the dominant treatment (Table 3).

This analysis showed that administration of EPFX had $99.3 \%, 99.5 \%$ and $99.9 \%$ respective probabilities of being cost-effective compared with vancomycin at
Table 3 Results (per patient) of the base case (deterministic) and probabilistic analyses

\begin{tabular}{|c|c|c|c|c|c|}
\hline \multicolumn{6}{|c|}{ Base case (deterministic) analysis } \\
\hline Treatment & Cost & QALY & Cost difference & QALY difference & ICER \\
\hline EPFX & $€ 10,046$ & 0.638 & $-€ 647$ & 0.044 & EPFX dominates \\
\hline Vancomycin & $€ 10,693$ & 0.594 & & & \\
\hline \multicolumn{6}{|c|}{ Probabilistic analysis } \\
\hline Treatment & Cost & QALY & Cost difference & QALY difference & ICER \\
\hline EPFX & $€ 10,051$ & 0.635 & $-€ 646$ & 0.043 & EPFX dominates \\
\hline Vancomycin & $€ 10,697$ & 0.592 & & & \\
\hline
\end{tabular}

$Q A L Y$ quality-adjusted life-years, $E P F X$ extended-pulsed fidaxomicin, ICER incremental cost-effectiveness ratio (cost per QALY gained with the most effective treatment) 
willingness-to-pay thresholds of $€ 20,000, € 25,000$ and $€ 30,000$ per QALY gained. EPFX was therefore dominant over vancomycin.

\section{Discussion}

Our analysis of the treatment of CDI in patients aged 60 years and older revealed that the EPFX regimen was associated with a gain of 0.044 QALYs and a cost saving of $€ 647$ per patient compared with vancomycin. The EPFX regimen is a costeffective treatment in most of the comparative analyses with vancomycin using the range of willingness-to-pay thresholds previously suggested for the NHS in Spain [36, 37].

Any evaluation of our results must take into account both the strengths and potential limitations. Regarding the limitations, it should be borne in mind that this is a theoretical model which is, by definition, a simplified simulation of reality. Also, assumptions had to be made in the model with respect to second- and third-line treatment sequences, and with regard to recurrences, as there was no follow-up of patients who failed to respond to the initial treatment in the EXTEND study [20]. In our model, FMT was the third-line treatment, although this practice is not widespread in Spain, highlighting the differences between clinical practice and recommendations in local, national and international treatment guidelines. However, this was regarded as the superior option as it is recommended by ESCMID and IDSA in the case of multirecurrent CDI $[10,11]$. Owing to the need to complete the model in a way that was fair to both treatment options, two assumptions were applied with regard to third-line treatment: (i) clinical cure would occur in all cases and (ii) there would be no further recurrences. These assumptions were validated by the five clinical experts (authors JMA, BA, JC, SG, MS). Moreover, the same mortality rate was assumed regardless of whether patients received EPFX or vancomycin. In the EXTEND study, one treatment-related death occurred in a patient in the vancomycin treatment arm [20]. The costs associated with recurrent episodes of CDI were assumed to be the same as those for the initial episode. This assumption was conservative, as recurrent CDI episodes can incur higher hospitalisation costs compared with initial episodes in clinical practice [38], although a recent study that estimated resource utilisation for the treatment of initial and recurrent CDI was contradictory, finding higher treatment costs for initial compared with recurrent CDI episodes [39].

The state utilities were not obtained from the EXTEND study, but rather from two published studies: one in patients with CDI, including recurrent CDI [28], and the other in patients with CDI who developed infected wounds following surgery for bone fractures [29]. Regarding the validity of performing our model from a Spanish healthcare perspective and sourcing utility data from other countries, it is notable that in a study based on 83,000 assessments of $44 \mathrm{EQ}-5 \mathrm{D}$ health states from six European countries, including Spain, there was greater variability between individuals than between countries [40]. All the costs used in our model were taken from Spanish sources [6, 25-27].

The conservative nature of our model did not allow for the inclusion of potential costs associated with reducing the risk of transmission of infection, patient isolation and infection control measures, such as the use of disposable gloves and gowns. As has previously been suggested for standardregimen fidaxomicin [23], had these costs been included in our model, the results are likely to have been even more favourable for EPFX owing to the lower recurrence rate compared with vancomycin.

The structure of the current model is the same as the one used in a recently published study from the United Kingdom [21]. As in our analysis, the study conducted in the United Kingdom concluded that the EPFX regimen would be the dominant treatment - both cost-saving and more effective than vancomycin [21] — with the cost of a treatment cycle of vancomycin in the United Kingdom being considerably higher than the current regimen in Spain ( $€ 214$ and $€ 34.50$, respectively) [21, 25]. The probability that first-line EPFX was cost-effective at a willingness-to-pay threshold of $£ 30,000 / \mathrm{QALY}$ was $76 \%$ for the patients in the United Kingdom [21].

The EXTEND study demonstrated sustained clinical cure of CDI and significantly lower recurrence rates with EPFX than with vancomycin in a population of patients aged 60 years and older [20]. The results of this economic model suggest that first-line treatment with EPFX would be cost-effective compared with vancomycin according to the willingness-topay thresholds normally considered in Spain.

Authors' contributions E. González Antona Sánchez, C. López Gutiérrez, C. Rubio-Terrés and D. Rubio-Rodríguez adapted the economic model for this analysis. C. Rubio-Terrés and D. Rubio-Rodríguez wrote the first and subsequent versions of the manuscript. All the authors contributed to fruitful discussion of the results and to the review of the manuscript. C. Rubio-Terrés is the guarantor of the overall content of the paper.

Funding Financial support for this manuscript was provided by Astellas Pharma Spain. Editorial support was provided by Rhian Harper Owen $\mathrm{PhD}$ for Cello Health MedErgy (Europe), and was funded by Astellas Pharma Global Development. Astellas Pharma is the holder of marketing authorisation for fidaxomicin in Spain.

Data availability Access to anonymised individual patient level data will not be provided for this trial as it meets one or more of the exceptions described under the Sponsor Specific Information for Astellas on www. clinicalstudydatarequest.com.

\section{Compliance with ethical standards}

Conflict of interest E. González Antona Sánchez and C. López Gutiérrez were employees of Astellas Pharma Spain at the time of 
preparing this manuscript. C. Rubio-Terrés and D. Rubio-Rodríguez received an honorarium from Astellas Pharma Spain in connection with the development of this manuscript. The remaining authors have no competing interests to declare.

Ethical approval This article does not contain any studies with human participants or animals performed by any of the authors.

Informed consent This was a retrospective study and all patient data were anonymised; informed consent was therefore not required under country-specific regulations. No direct access to source data by the clinical research organisation or the sponsor was allowed.

Open Access This article is distributed under the terms of the Creative Commons Attribution 4.0 International License (http:// creativecommons.org/licenses/by/4.0/), which permits unrestricted use, distribution, and reproduction in any medium, provided you give appropriate credit to the original author(s) and the source, provide a link to the Creative Commons license, and indicate if changes were made.

\section{References}

1. Bassetti M, Villa G, Pecori D, Arzese A, Wilcox M (2012) Epidemiology, diagnosis and treatment of Clostridium difficile infection. Expert Rev Anti-Infect Ther 10:1405-1423. https://doi.org/ 10.1586/eri.12.135

2. Alcala L, Marin M, Martin A, Sanchez-Somolinos M, Catalan P, Pelaez MT et al (2011) Laboratory diagnosis of Clostridium difficile infection in Spain: a population-based survey. J Hosp Infect 79:1317. https://doi.org/10.1016/j.jhin.2011.05.017

3. Alcala L, Martin A, Marin M, Sanchez-Somolinos M, Catalan P, Pelaez T et al (2012) The undiagnosed cases of Clostridium difficile infection in a whole nation: where is the problem? Clin Microbiol Infect 18:E204-E213. https://doi.org/10.1111/j.1469-0691.2012. 03883.x

4. Asensio A, Vaque-Rafart J, Calbo-Torrecillas F, Gestal-Otero JJ, Lopez-Fernandez F, Trilla-Garcia A, et al. (2008) Increasing rates in Clostridium difficile infection (CDI) among hospitalised patients, Spain 1999-2007. Euro Surveill;13. https://doi.org/10.2807/ese.13. 31.18943-en

5. van Kleef E, Green N, Goldenberg SD, Robotham JV, Cookson B, Jit $\mathrm{M}$ et al (2014) Excess length of stay and mortality due to Clostridium difficile infection: a multi-state modelling approach. $\mathrm{J}$ Hosp Infect 88:213-217. https://doi.org/10.1016/j.jhin.2014.08. 008

6. Asensio A, Bouza E, Grau S, Rubio-Rodriguez D, Rubio-Terres C (2013) Cost of Clostridium difficile associated diarrhea in Spain. Rev Esp Salud Publica 87:25-33. https://doi.org/10.4321/S113557272013000100004

7. Olsen MA, Yan Y, Reske KA, Zilberberg M, Dubberke ER (2015) Impact of Clostridium difficile recurrence on hospital readmissions. Am J Infect Control 43:318-322. https://doi.org/10.1016/j.ajic. 2014.12.020

8. Reigadas Ramirez E, Bouza ES (2018) Economic burden of Clostridium difficile infection in European countries. Adv Exp Med Biol 1050:1-12. https://doi.org/10.1007/978-3-319-7279981

9. Johnson AP, Wilcox MH (2012) Fidaxomicin: a new option for the treatment of Clostridium difficile infection. J Antimicrob Chemother 67:2788-2792. https://doi.org/10.1093/jac/dks302
10. McDonald LC, Gerding DN, Johnson S, Bakken JS, Carroll KC, Coffin SE et al (2018) Clinical Practice Guidelines for Clostridium difficile Infection in Adults and Children: 2017 Update by the Infectious Diseases Society of America (IDSA) and Society for Healthcare Epidemiology of America (SHEA). Clin Infect Dis 31: 431-455. https://doi.org/10.1093/cid/cix1085

11. Debast S, Bauer M, Kuijper E (2014) European society of clinical microbiology and infectious diseases: update of the treatment guidance document for Clostridium difficile infection. Clin Microbiol Infect 20:1-26. https://doi.org/10.1111/1469-0691.12418

12. Kelly CP (2012) Can we identify patients at high risk of recurrent Clostridium difficile infection? Clin Microbiol Infect 18:21-27. https://doi.org/10.1111/1469-0691.12046

13. Britton RA, Young VB (2012) Interaction between the intestinal microbiota and host in Clostridium difficile colonization resistance. Trends Microbiol 20:313-319. https://doi.org/10.1016/j.tim.2012. 04.001

14. Crawford T, Huesgen E, Danziger L (2012) Fidaxomicin: a novel macrocyclic antibiotic for the treatment of Clostridium difficile infection. Am J Health Syst Pharm 69:933-943. https://doi.org/10. 2146/ajhp110371

15. Louie TJ, Cannon K, Byrne B, Emery J, Ward L, Eyben M et al (2012) Fidaxomicin preserves the intestinal microbiome during and after treatment of Clostridium difficile infection (CDI) and reduces both toxin re-expression and recurrence of CDI. Clin Infect Dis 55(Suppl 2):S132-S142. https://doi.org/10.1093/cid/cis338

16. Louie TJ, Miller MA, Mullane K, Weiss K, Lentnek A, Golan Y et al (2011) Fidaxomicin versus vancomycin for Clostridium difficile infection. N Engl J Med 364:422-431. https://doi.org/10. 1056/NEJMoa0910812

17. Cornely OA, Crook DW, Esposito R, Poirier A, Somero MS, Weiss $\mathrm{K}$ et al (2012) Fidaxomicin versus vancomycin for infection with Clostridium difficile in Europe, Canada, and the USA: a doubleblind, non-inferiority, randomised controlled trial. Lancet Infect Dis 12:281-289. https://doi.org/10.1016/S1473-3099(11)70374-7

18. Crook DW, Walker AS, Kean Y, Weiss K, Cornely OA, Miller MA, et al. (2012) Fidaxomicin versus vancomycin for Clostridium difficile infection: meta-analysis of pivotal randomized controlled trials. Clin Infect Dis;55 Suppl 2:S93-103. https://doi.org/10.1093/ cid/cis499

19. Chilton CH, Crowther GS, Todhunter SL, Ashwin H, Longshaw CM, Karas A et al (2015) Efficacy of alternative fidaxomicin dosing regimens for treatment of simulated Clostridium difficile infection in an in vitro human gut model. J Antimicrob Chemother 70:25982607. https://doi.org/10.1093/jac/dkv156

20. Guery B, Menichetti F, Anttila V, Adomakoh N, Aguado JM, Bisnauthsing K et al (2017) Extended-pulsed fidaxomicin versus vancomycin for Clostridium difficile infection in patients 60 years and older (EXTEND): a randomised, controlled, open-label, phase 3b/4 trial. Lancet Infect Dis 18:296-307. https://doi.org/10.1016/ S1473-3099(17)30751-X

21. Cornely OA, Watt M, McCrea C, Goldenberg SD, De Nigris E (2018) Extended-pulsed fidaxomicin versus vancomycin for Clostridium difficile infection in patients aged $\geq 60$ years (EXTEND): analysis of cost-effectiveness. J Antimicrob Chemother 73:2529-2539. https://doi.org/10.1093/jac/dky184

22. Rubio-Terrés C, Echevarría A (2006) Modelos de Markov: Una herramienta útil para el análisis farmacoeconómico. PharmacoEconomics Spanish Research Articles (Suppl 2) 3:7178. http://www.healthvalue.org/pdfs/pharmacoeconomics\%20sra\% 202006d.pdf

23. Rubio-Terrés C, Cobo Reinoso J, Grau Cerrato S, Mensa Pueyo J, Salavert Lleti M, Toledo A et al (2015) Economic assessment of fidaxomicin for the treatment of Clostridium difficile infection (CDI) in special populations (patients with cancer, concomitant antibiotic treatment or renal impairment) in Spain. Eur J Clin 
Microbiol Infect Dis 34:2213-2223. https://doi.org/10.1007/ s10096-015-2472-0

24. Fekety R, McFarland LV, Surawicz CM, Greenberg RN, Elmer GW, Mulligan ME (1997) Recurrent Clostridium difficile diarrhea: characteristics of and risk factors for patients enrolled in a prospective, randomized, double-blinded trial. Clin Infect Dis 24:324-333. https://doi.org/10.1093/clinids/24.3.324

25. Consejo General de Colegios Oficiales de Farmacéuticos. BOT Plus 2.0 [Internet]. https://botplusweb.portalfarma.com/

26. Isla D, De Castro J, Juan O, Grau S, Orofino J, Gordo R et al (2017) Costs of adverse events associated with erlotinib or afatinib in firstline treatment of advanced EGFR-positive non-small cell lung cancer. Clinicoecon. Outcomes Res 9:31-38. https://doi.org/10.2147/ CEOR.S121093

27. Servicio Vasco de Salud (2017) Tarifas para facturación de servicios sanitarios y docentes de osakidetza para el año 2017 [Internet]. https://www.osakidetza.euskadi.eus/contenidos/informacion/libro_ tarifas/eu_libro/adjuntos/Libro_de_Tarifas_2017.pdf

28. Wilcox $\bar{M}$, Ahir H, Coia JE, Dodgson $\bar{A}$, Hopkins S, Llewelyn MJ et al (2017) Impact of recurrent Clostridium difficile infection: hospitalization and patient quality of life. J Antimicrob Chemother 72:2647-2656. https://doi.org/10.1093/jac/dkx174

29. Slobogean GP, O’Brien PJ, Brauer CA (2010) Single-dose versus multiple-dose antibiotic prophylaxis for the surgical treatment of closed fractures. Acta Orthop 81:256-262. https://doi.org/10. 3109/17453671003587119

30. National Institute for Health and Care Excellence (2011) Pazopanib for the first-line treatment of advanced renal cell carcinoma. Technology appraisal guidance [TA215] [Internet]. https://www. nice.org.uk/guidance/ta215/chapter/1-Guidance

31. Shyangdan D, Jacob RP, Connock M, Johnston R, Cummins E, Waugh N (2014) Empagliflozin for the treatment of type 2 diabetes: a single technology assessment.. Warwick Evidence [Internet]. https://njl-admin.nihr.ac.uk/document/download/2022671

32. Marti SG, Colantonio L, Bardach A, Galante J, Lopez A, Caporale J et al (2013) A cost-effectiveness analysis of a 10-valent pneumococcal conjugate vaccine in children in six Latin American countries. Cost Eff Resour Alloc 11:21. https://doi.org/10.1186/1478$7547-11-21$

33. National Institute for Health and Care Excellence (2015) Bortezomib for previously untreated mantle cell lymphoma.
Technology appraisal guidance [TA370] [Internet]. https://www. nice.org.uk/guidance/ta370/resources/bortezomib-for-previouslyuntreated-mantle-cell-lymphoma-pdf-82602782522053

34. Monge D, Millan I, Gonzalez-Escalada A, Asensio A (2013) The effect of Clostridium difficile infection on length of hospital stay. A cohort study. [In Spanish] Enferm Infecc Microbiol Clin 31:660664. https://doi.org/10.1016/j.eimc.2012.11.007

35. Briggs A, Claxton K, Sculpher M (2006) Decision modelling for health economic evaluation. Handbooks in health economic evaluation. Oxford University Press, New York

36. Vallejo-Torres L, García-Lorenzo B, Castilla I, Valcárcel Nazco C, García-Pérez L, Linertová R, et al. Valor Monetario de un Año de Vida Ajustado por Calidad: Estimación empírica del coste de oportunidad en el Sistema Nacional de Salud. Informes de Evaluación de Tecnologías Sanitarias SESCS. 2015 [Internet]. https://www3.gobiernodecanarias.org/sanidad/scs/content/ 3382aaa2-cb58-11e5-a9c5-a398589805dc/SESCS\%202015 Umbral\%20C.O.\%20AVAC.pdf

37. Sacristan JA, Oliva J, Del Llano J, Prieto L, Pinto JL (2002) What is an efficient health technology in Spain? [In Spanish] Gac Sanit 16: 334-343. [Internet]. http://scielo.isciii.es/scielo.php?script=sci arttext\&pid=S0213-91112002000400008

38. Dubberke ER, Schaefer E, Reske KA, Zilberberg M, Hollenbeak CS, Olsen MA (2014) Attributable inpatient costs of recurrent Clostridium difficile infections. Infect Control Hosp Epidemiol 35:1400-1407. https://doi.org/10.1086/678428

39. Zhang D, Prabhu VS, Marcella SW (2018) Attributable healthcare resource utilization and costs for patients with primary and recurrent Clostridium difficile infection in the United States. Clin Infect Dis 66:1326-1332. https://doi.org/10.1093/cid/cix1021

40. Greiner W, Weijnen T, Nieuwenhuizen M, Oppe S, Badia X, Busschbach J et al (2003) A single European currency for EQ-5D health states. Results from a six-country study. Eur J Health Econ 4: 222-231. https://doi.org/10.1007/s10198-003-0182-5

Publisher's Note Springer Nature remains neutral with regard to jurisdictional claims in published maps and institutional affiliations. 